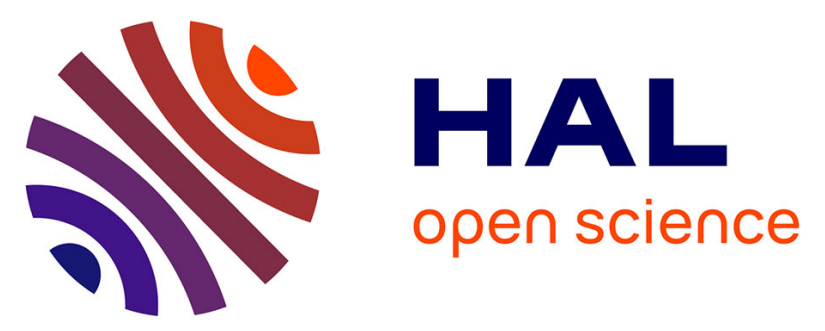

\title{
Comparison between thermal airborne remote sensing, multi-depth electrical resistivity 1 profiling and soil mapping: an example in Beauce (Loiret, France)
}

Catherine Pasquier, Hocine Bourennane, Isabelle Cousin, Maud Seger, Michel Dabas, Julien Thiesson, Alain Tabbagh

\section{To cite this version:}

Catherine Pasquier, Hocine Bourennane, Isabelle Cousin, Maud Seger, Michel Dabas, et al.. Comparison between thermal airborne remote sensing, multi-depth electrical resistivity 1 profiling and soil mapping: an example in Beauce (Loiret, France). Near Surface Geophysics, 2016, 14 (4), pp.345 356. 10.3997/1873-0604.2016021 . hal-01376239

\section{HAL Id: hal-01376239 \\ https://hal.sorbonne-universite.fr/hal-01376239}

Submitted on 4 Oct 2016

HAL is a multi-disciplinary open access archive for the deposit and dissemination of scientific research documents, whether they are published or not. The documents may come from teaching and research institutions in France or abroad, or from public or private research centers.
L'archive ouverte pluridisciplinaire HAL, est destinée au dépôt et à la diffusion de documents scientifiques de niveau recherche, publiés ou non, émanant des établissements d'enseignement et de recherche français ou étrangers, des laboratoires publics ou privés. 
4 Catherine Pasquier ${ }^{1}$, Hocine Bourennane ${ }^{1}$, Isabelle Cousin ${ }^{1}$, Maud Séger ${ }^{1}$, Michel Dabas ${ }^{2}$,

5 Julien Thiesson ${ }^{3}$, Alain Tabbagh ${ }^{3}$

Comparison between thermal airborne remote sensing, multi-depth electrical resistivity profiling and soil mapping: an example in Beauce (Loiret, France)

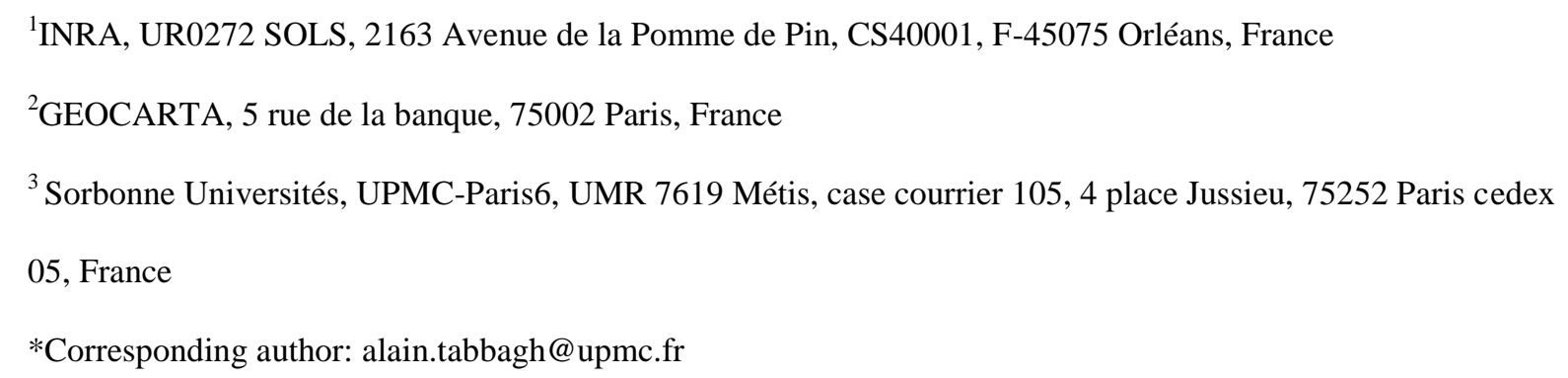

\section{Abstract}

A wide variety of remote sensing and ground-based (proximal sensing) methods have been developed to describe soil's physical properties and their lateral variations. Remote sensing enables the estimation of soil properties over large areas, but the information is often limited to the soil surface. Ground-based methods enable the derivation of soil properties for the whole soil thickness, although these methods cannot be conducted over large areas. The aim of the present study is to contribute to the assessment of the efficacy of airborne thermal prospection over bare soils in soil mapping. This study focuses on a comparison between this technique, which can investigate over the whole soil thickness after a sufficiently long transient heat exchange period, and pedological and electrical resistivity data that were recorded for three different depths of investigation.

The study area is located in the Beauce region, where the soils (haplic Calcisol or calcaric Cambisol) consist of a loamy-clay layer that is 0.3 to $1.4 \mathrm{~m}$ thick and overlies Tertiary Beauce limestone. Thermal measurements were recorded by ARIES radiometer in 
December after 6 days of heat loss from the ground. The investigation depth could thus be considered to be larger than the thickness of the ploughed layer. Comparisons using statistical analyses between the thermal measurements, electrical resistivity and pedological data demonstrated that i) the spatial organization of the thermal inertia map is similar to the spatial organization of the $0-1.7 \mathrm{~m}$ resistivity map and ii) the thermal apparent inertia values were significantly different between the haplic Calcisols and the calcaric Cambisols and can thus be mapped with a high spatial resolution over large areas.

The applicability of thermal prospecting in soil mapping opens large perspectives considering the present advances in light infrared radiometers. Beside agronomical concerns this methodology will also facilitate important progresses in engineering applications among which the cross estimation of electrical and thermal properties.

Keywords: Thermal infrared airborne remote sensing, soil physical property mapping, thermal inertia, electrical resistivity, ARP

\section{Introduction}

Knowledge of the spatial variability of soils is of major importance for a wide variety of agronomic, industrial and environmental applications. The classification of soils is based on soil properties materials, which are defined in terms of diagnostic horizons (FAO, 2006). The properties that characterize soil classes play a significant role in the agronomic potentiality of cultivated fields and in most geotechnical engineering projects, such as the installation of buried pipes or high power electrical cables or the delineation of polluted areas. In all these cases, the soil classes and matched properties must be spatially described at a high 
resolution, metric or decametric. For this purpose, the use of non-destructive geophysical methods is of major interest. Indeed, geophysical methods enable the measurement of soil physical properties rapidly and with a quasi-exhaustive covering. A wide variety of airborne and ground based geophysical methods have been developed.

Airborne techniques enable the estimation of soil properties over large areas, but most of them, for example, visible near-infrared (VNIR) reflectance data or radar backscattering, are often limited to the soil surface; in particular, the latter is limited to several centimeters (Nichols et al. 2011). In contrast, ground-based methods enable the derivation of soil properties over the whole soil thickness of pedological/agronomical interest (Viscarra Rossel et al. 2010) and to characterize the parent rock, but these methods cannot be conducted for large areas. Despite this limitation, the electrical resistivity of soils has been measured for twenty years (e.g. Samouelian et al. 2005), notably in the context of precision agriculture. The electrical resistivity of the soil is related to several soil properties, mainly porosity, clay content and water content: a wet soil is more electrically conductive than a drier soil (Samouëlian et al. 2005, Cousin et al. 2009). Because of the wide range of values exhibited by this property, which is associated with the easiness and reliability of its measurement, the DC resistivity technique is considered as a reference for testing the efficacy of other methods (Gebbers et al. 2009). Among airborne techniques, thermal prospection can be used to investigate the whole soil thickness (Scollar et al. 1990) and over large areas. This method is ancient (Kappelmeyer 1957, Krcmar and Masin 1970), but its ground-level applications have been rather limited by the necessity to correct diurnal soil temperature variations during the implementation of the survey. Fortunately, this limitation is overcome by remote infrared radiometric measurements, where the duration for measuring the whole area remains small against the soil surface temperature time variations. Satellite-borne scanner radiometers currently do not offer sufficient ground resolution, but airborne archaeological prospection 
was initiated forty years ago (Périsset and Tabbagh 1981), taking advantage of favorable heat exchange conditions at the ground surface that correspond to transient, several-day-long weather changes. The experience that is acquired in archaeological prospection can be transferred to agronomy-driven soil management studies. Additionally, the development of new light thermal cameras that can be borne either by small planes or even by unmanned aerial vehicles has revived interest in thermal prospection (Schlerf et al. 2012).

The physical parameter that is measured by radiometers, the brightness temperature, depends on the soil emissivity and the thermometric temperature (see definitions in Appendix). Both can be of interest for geophysical exploration in the thermal infrared atmospheric window, which corresponds to the 8-14 $\mu \mathrm{m}$ wavelength range. The soil emissivity provides information about the soil surface mineralogy. The lateral changes in the heat exchange balance and/or in the soil thermal properties modify the thermometric temperature. Soil emissivity can be directly used to map rocks or regoliths in arid climatic zones where pedogenesis is not active (Kahle and Rowan 1980, Salisbury et al. 1994, Watson et al. 1996, Kato et al. 2014), but it has no direct application in temperate humid climates, where soil moisture and organic matter make this parameter uniform. In the presence of vegetation, the plant temperature is governed by its evapotranspiration, and this predominant term of the heat exchange balance can consequently be assessed (Choudury et al. 1986, Hilker et al. 2013, Mallick et al. 2014). For bare soils, the lateral variations in the soil surface temperature depend either on modification to the heat balance terms because of the surface slope (Fourteau and Tabbagh 1979) or on changes in underground thermal properties (Gauthier and Tabbagh 1994) reflecting the ease with which heat (positive or negative) can be moved downward into the ground. For a homogeneous solid and unsteady heat inputs/outputs, the temperature changes are inversely proportional to the thermal inertia, which is expressed by $P=\sqrt{K C_{v}}$, where $K$ is the thermal conductivity and $C_{v}$ is the volumetric heat capacity 
(see appendix for de definition of thermal properties). Thus, the results of a thermal prospection can be expressed in terms of variations in the soil's apparent thermal inertia (Price 1977): the thermal inertia of a homogeneous ground having the same surface

105

temperature in the same flux conditions. However, in presence of a tilled layer it is more relevant to consider a two layer model with topsoil (i.e. the surface soil or the tilled layer) above homogeneous subsoil beneath. The reason for this is because the topsoil's properties (namely the bulk density) are homogenized by tillage and fauna activity at the plot scale (Tabbagh 1976). The inversion used hereafter will transform the brightness temperature variations in subsoil's thermal inertia variations.

The key point of thermal prospection is the evaluation of the weather conditions under which the investigation depth would be larger than the ploughed layer. Contrary to other prospection techniques, this depth does not depend on the choice of a frequency or other instrument parameters but on the history of the heat exchange at the ground surface before the measurement time. The daily heat flux variation is too rapid to significantly influence subsoil temperature, and longer transient variations must be considered: if the duration of a transient input (or output) of heat lasts one or two days, the investigation depth would be limited to approximately $25 \mathrm{~cm}$, while the depth would reach $1 \mathrm{~m}$ if the transient input (or output) lasts one week or more (Périsset and Tabbagh 1981).

The present study focuses on the ability of thermal airborne remote sensing techniques - thermal prospection for exploration geophysicists - to discriminate soil classes. The experiment was conducted on a cultivated field in the Beauce region, France. The soil classes and their spatial variability in this field were widely known because a soil map had been drawn before the experiment (Nicoullaud et al., 2004). The study zone consists of haplic Calcisols and calcaric Cambisols (IUSS Working Group WRB, 2006). The surface temperature variations were recorded by using an airborne radiometer, and then the thermal 
inertia of the subsoil layer was calculated by using the transient heat flux values, which were determined at the nearby Bricy meteorological station. A geoelectrical prospection was conducted on the same field to compare the two types of geophysical methods and their investigation depths. First, the thermal inertia and electrical resistivity are compared to the soil properties, which were locally measured by auger drilling, and then to the soil classes, which were described on the soil map. Finally, a statistical methodology is proposed to transform the thermal inertia map into a map of soil types.

\section{Materials and methods}

\section{Study site and soil description}

The study area consists of one 39 ha plot (plot A) in the Beauce region (Villamblain, Loiret, France), where the soil thickness varies from 0.3 to $1.4 \mathrm{~m}$ over Tertiary Beauce limestone (Fig. 1). Figure 1 presents the soil map - realized in 2000 before and independently of the airborne prospection described here - that was made from the description of 110 auger soil samples. Soil auger hole sampling was conducted on transects that were spaced every 100 m. Soil scientists selected samples from the transects based on previous surveys, surface observations and topography. Sometimes, a soil sample was added between transects when observations were different between two nearby auger holes.

The two soil types that were found (haplic Calcisol and Calcaric Cambisol) consist of a loamy-clay layer that developed on a lacustrine limestone deposit. The difference between these two soil types is the calcareous content in the topsoil: haplic Calcisols are soils with a significant accumulation of secondary calcium carbonates but are non-calcareous (less than $10 \% \mathrm{CaCO}_{3}$ ), while calcaric Cambisol topsoil is calcareous. The soil units were determined by simple observation, without soil analysis. Three sub-units were described for the haplic Calcisols and eight sub-units for the calcaric Cambisols, which depended on the 
thickness of the loamy-clay layer, the carbonate content, the stone content, the type of calcareous content (cryoturbated or not) and the depth of the bedrock (Nicoullaud et al. 2004). These two soil types may differ in terms of agronomy: an abundance of calcium can block elemental nutrients, and high limestone content in soils is unfavorable for rooting. Most Calcisols have a medium or fine soil texture and good water-holding properties.

\section{DC electrical prospection}

A multi-depth resistivity map was created by an ARP® device in August 2012 over a 9 ha study area (zone B), a part of plot A. This ARP@ system (Figure 2) is a mobile, multidepth soil electrical resistivity mapping system that comprises one injection dipole $(\mathrm{AB})$ and three V-shaped measuring dipoles (M1 N1, M2 N2 and M3 N3) (Panissod et al. 1997, Dabas, 2009). The distance between the injection dipole and the measuring dipoles is $0.5 \mathrm{~m}$ for the $\mathrm{V} 1$ array (A B- M1 N1), $1 \mathrm{~m}$ for the V2 array (A B-M2 N2) and $1.7 \mathrm{~m}$ for the V3 array (A BM3 N3). The investigation depths roughly correspond to the distance between the AB dipoles and $\mathrm{MN}$ dipoles (Figure 3: $0.5 \mathrm{~m}, 1.0 \mathrm{~m}$ and $1.7 \mathrm{~m}$ for $\mathrm{V} 1, \mathrm{~V} 2$ and $\mathrm{V} 3$, respectively). Resistivity measurements were recorded every $20 \mathrm{~cm}$ along profiles spaced $6 \mathrm{~m}$ apart. After filtering the measurements, the resistivity data were interpolated on regular grids by the inverse distance weighted method.

To compare with the subsoil's thermal inertia variations, the three apparent electrical resistivity values were interpreted by using a 1D two layer model (Meheni et al. 1996) to estimate the resistivity of the subsoil layer (depth $>0.25 \mathrm{~m}$ ). The following parameters were used to process the inversion: the ploughed surface had a thickness equal to $0.25 \mathrm{~m}$ according to the 21 auger hole prospection, and its resistivity was estimated to be equal to $40 \Omega . \mathrm{m}$. This resistivity value was estimated from the established relationship between the interpreted electrical resistivity and the volumetric water content of the topsoil, which was recorded by 
TDR probes at the same study site, according to the formula for this pedological context (Cousin et al. 2009), $\rho=-129 \operatorname{Ln}(\theta)+456$, where $\rho$ is the resistivity value and $\theta$ is the volumetric water content. Indeed, calibrated TDR probes were installed at North-East from plot A. The interpreted electrical resistivity and water content were recorded at two depths of the topsoil layer (12 and $20 \mathrm{~cm}$ depth, respectively) at 23 dates during a year at 2 measurements positions. Thus, the relationship mentioned above was established on 92 measurements. $\theta$ in the relationship by Cousin et al., 2009 was inferred on the base of the volumetric water content measured during the acquisition period of the electrical resistivity data. $\theta$ was equal to $0.355 \mathrm{~m}^{3} \mathrm{~m}^{-3}$ (mass water content $\mathrm{x}$ bulk density: $0.25 \mathrm{~g} \mathrm{~g}^{-1} \times 1.42 \mathrm{~g} \mathrm{~cm}^{-}$ $\left.{ }^{3}\right)$.The resolution of the grid map was $1.7 \mathrm{~m}$ (Figure 3).

\section{Auger soil sample information}

A total of 21 auger holes were regularly dug during the electrical prospection (Figure 3) to describe and sample the successive horizons. The auger hole depths range from 30 to $120 \mathrm{~cm}$. The soil horizons were classified into the A horizon (topsoil, LA, tilled layer, usually $0.25 \mathrm{~m}$ thick), B horizon (subsoil, Sci or Sca, horizons under the tilled layer) and C horizon (corresponding to the bedrock). Depending on the location, the soil profiles were characterized by an $\mathrm{A} / \mathrm{B}$ sequence, an $\mathrm{A} / \mathrm{C}$ sequence, or an $\mathrm{A} / \mathrm{B} / \mathrm{C}$ sequence. All of the soil samples were analyzed at the INRA Arras Laboratory (Arras, Pas de Calais, France) to determine (1) the soil texture by using ISO 10693 method (5 particle size fractions with no decarbonization) and (2) the soil $\mathrm{CaCO}_{3}$ content by using the NF ISO 10693 volumetric method. Each of the 21 auger holes was affiliated to a soil type according to the soil map of the study area.

\section{Thermal prospection}



two numerical channels: one in the visible and near infrared ranges $(0.5-1 \mu \mathrm{m})$, and the other in the thermal infrared range (10.5-12.5 $\mu \mathrm{m})$ (Monge and Sirou 1975, Beaufrère et al. 1999) with an $\mathrm{Hg}-\mathrm{Cd}-\mathrm{Te}$ photoconduction detector. Two internal blackbodies allowed the translation of the recorded video signal into the brightness temperature. The data were acquired on December 11, 2002 at $10 \mathrm{~h} 40$ U.T. at a flight altitude of $1006 \mathrm{~m}$ and an IFOV (Instantaneous Field Of View) of $6.25 \mathrm{~m}^{2}$ at nadir, while the sampling step along the line was $1.75 \mathrm{~m}$. The mirror rotated at $36.4 \mathrm{~Hz}$, and the speed of the plane was $56.6 \mathrm{~ms}^{-1}$. In the temperature signal, the least significant bit (LSB) corresponded to $0.044 \mathrm{~K}$ resolution. The data were corrected for pitch and roll (with data from the gyroscope) and anamorphic distortion before a last geometric rectification in the GIS. Finally, the measurements were represented on a $1.6 \mathrm{~m}$ by $1.6 \mathrm{~m}$ grid.

The heat flux variations at the soil surface were calculated from soil temperature data that were recorded at the nearby (20 km east) Bricy meteorological station at 10, 20, 50 and $100 \mathrm{~cm}$ depths by using the algorithm that is described in Scollar et al. (1990), which is recalled in Appendix III. These values are presented in Figure 6 from the 15th of November to the $15^{\text {th }}$ of December. The soil cooling was significant, especially during the six days that preceded the flight. The investigation depth can thus be considered to be greater than the thickness of the ploughed layer (Scollar et al. 1990) and qualitatively the thermal inertia of the subsoil is higher where the measured ground surface temperature is higher and lower where the temperature is lower. Under the hypothesis that the observed temperature lateral variations originate in variations of the subsoil thermal inertia it is possible to establish a quantitative correspondence between the brightness temperature and this thermal inertia using a two layer forward model. In this calculation, the heat flux variations are considered as series 
226 of successive $\frac{\partial Q}{\partial \tau}$ variations, so that the resultant ground surface temperature $T(t)$ on time $t$

227 can be expressed by:

228

$$
T(t)=\int_{0}^{t} \frac{\partial Q}{\partial \tau} \operatorname{Step}(t-\tau) d \tau
$$

The two layers step response has for expression (Tabbagh 1973):

$$
\text { Step }(t-\tau)=\frac{2 \sqrt{t-\tau}}{P_{1}}\left[\frac{1}{\sqrt{\pi}}+2 \sum_{n=1}^{\infty}(-C)^{n} \operatorname{ierfc}\left(\frac{n h}{\sqrt{\Gamma_{1}(t-\tau)}}\right)\right] \text {, }
$$

where $P_{1}$ is the thermal inertia of the first layer (topsoil), $h$ its thickness, $\Gamma_{1}$ its thermal

diffusivity, ierfc is the integral of the complementary error function and $C=\frac{P_{2}-P_{1}}{P_{2}+P_{1}}$ is the

When $P_{2}=P_{1}$, the step response reduces to:

For this correspondence calculation we the assumed the uniform topsoil layer has a thickness $h=25 \mathrm{~cm}$, a thermal diffusivity of $\Gamma_{l}=0.48 \mathrm{~m}^{2} \mathrm{~s}^{-1}$ and a $P_{l}=1732$ S.I. thermal inertia and we fixed the 128 signal value at $5.63{ }^{\circ} \mathrm{C}$ (using both in-flight radiometer calibration and ground control points). The resulting apparent thermal inertia of the subsoil map is shown in Figures 3 and 7.

\section{Data analysis}

The approach that was developed to assess the information from the thermal survey is summarized in Figure 8. The approach involves 4 steps.

First, Principal Component Analysis (PCA) was used to analyze the overall variation in the data (soil properties, thermal inertia and electrical resistivity, step 1). The effect of soil 
type on the thermal inertia response and electrical resistivity response was assessed by using analysis of variance (ANOVA) (step 2). ANOVA tests the null hypothesis that samples in two or more groups are drawn from populations with the same mean values. ANOVA produces an F-statistic, which is the ratio of the variance that is calculated among the means to the variance within the samples. If the group means are drawn from populations with the same mean values, the variance between the group means should be lower than the variance of the samples. A higher ratio therefore implies that the samples were drawn from populations with different mean values.

Factorial discriminant analysis (FDA, step 3) was used to establish a classification model of the soil types in the study area according to the thermal inertia and electrical resistivity, respectively. For a detailed presentation, the reader can refer to books or papers on the subject, such as Tomassone et al. (1988), Tabachnick and Fidell (1996), and Bourennane et al. (2014). FDA is a statistical method for describing and forecasting. Its purpose is to study the relationship between a qualitative variable and a set of quantitative variables. The FDA can be considered as an extension of the regression problem, where the dependent variable is qualitative. The data consist of $n$ observations that are divided into $k$ classes or categories and described by $p$ variables. Traditionally, one can distinguish two aspects in discriminant analysis:

1. A descriptive aspect, which consists of finding linear combinations of variables that separate the $k$ categories and provide a graphic representation that adequately reflects this separation;

2. A decisional aspect, where a new individual arises for which we know the values of the predictors; this aspect decides which category it should be allocated to. In such cases, this is a classification problem. 
Two FDA models are possible based on a fundamental assumption: if we assume that the covariance matrices are identical, one can be used for linear factorial discriminant analysis. If we assume that the covariance matrices are different for at least two categories, we have a quadratic model. The box test allows testing of this hypothesis (Bartlett's approximation allows the use of a chi-square law for the test).

Finally, the discriminant function from step 3 was applied to map the soil types over the whole study area (step 4).

\section{Results and discussion}

\section{Soil data: descriptive statistics}

The soil textures (Figure 4) are represented in the CEC85 triangle (Commission of the European Communities 1985). A particle size analysis of the samples shows that the Calcisols have mainly medium/fine texture, whereas the Cambisols have more variable textures ("fine", "medium/fine" or "medium"). The Cambisols appear to have some sandy particles, from 5 to $30 \%$, while the sandy content in the Calcisols does not exceed $4 \%$ in the A horizon. The sandy soil texture is probably explained by the amount of coarse limestone particles. The boxplot (Figure 5) analysis that was performed on the 21 soil samples shows that the Calcisols have low $\mathrm{CaCO}_{3}$ content, specifically, less than $10 \mathrm{~g} \cdot \mathrm{kg}^{-1}$, conversely to the Cambisols. The soil types can be differentiated according to their texture and $\mathrm{CaCO}_{3}$ content.

\section{Thermal inertia and electrical resistivity maps}

The apparent thermal inertia of the subsoil in the study area varied between 916 and 2082 S.I. This value was lower in the western part of the studied plot and higher in the southeastern part (Figure 7). The apparent electrical resistivity over the 9 ha B plot varied between 11 and $68 \Omega . \mathrm{m}$ for the V1 array, between 17 and $90 \Omega . \mathrm{m}$ for the V2 array and between 14 and 127 S.m for the V3 array (Figure 3). For all the arrays, the spatial organization of the 
electrical resistivity was the same, with lower resistivity values to the northwest and higher resistivity values to the southeast. A low resistivity value band (oriented from northeast to southwest) crossed over the south-eastern part, which corresponds to a calcaric Cambisol that developed over a grey limestone soil unit. The inverted subsoil (using the same two-layer model geometry as for the thermal data) resistivity values were between 17 and $167 \Omega . m$ and exhibited a similar spatial pattern to the apparent resistivity values.

On the 9 ha B plot, the spatial pattern of the thermal inertia map was also very similar to the spatial pattern of the resistivity maps: areas with low resistivity corresponded to low thermal inertia areas and vice versa, except for the Cambisol that developed over the grey limestone soil unit to the south. In this soil unit, the inversed subsoil resistivity approximately was $35 \Omega . \mathrm{m}$, the thermal inertia was high., the soil depth was approximately $40 \mathrm{~cm}$. This soil unit likely was wet during the electrical prospecting (due to heavy rain).

In addition, Figure 7 shows that the airborne technique depends on any obstacles that are located between the soil and the sensor, unlike the ARP method. Indeed, we can spot ground cover, sprinkler lines, hedges and buildings.

\section{Principal Component Analysis between geophysical measurements and soil properties at} auger holes

The first principal component (Fig. 9 a and b) accounts for more than $80 \%$ of the total variation. Except for the clay content in the subsoil, this component is strongly correlated with all the original variables and is inversely correlated with the silt content, thermal inertia, electrical resistivity and $\mathrm{CaCO}_{3}$ contents. The $\mathrm{CaCO}_{3}$ and sand contents are strongly positively correlated in both layers (Figure $9 \mathrm{a}$ and b). Previous results have shown that no difference in clay content exists between Calcisols and Cambisols, thus, we can conclude that these soil properties (sand content and $\mathrm{CaCO}_{3}$ ) are well correlated and explain the higher 
electrical resistivity and thermal inertia in accordance with the general knowledge about these properties.

\section{Effect of soil type on the thermal inertia response and electrical resistivity at the auger}

\section{holes}

We studied the effect of soil type, a more inclusive variable than soil texture or $\mathrm{CaCO}_{3}$ content, on the geophysical measurements. An ANOVA analysis (performed on auger sample measurements $\mathrm{N}=21$ ), which used the Tukey pairwise means comparison method on the thermal inertia signal, showed a highly significant influence from the soil type (Table 1). An ANOVA test on the resistivity data provided similar results (Table 2), which means that both thermal and resistivity methods are efficient tools to differentiate soil types.

Thus, a quadratic factorial discriminant analysis (FDA) was performed to obtain a model that can map soil types by using exhaustive geophysical information. Confusion matrices (Table 3a) showed that the thermal inertia values enabled the accurate classification of $85 \%$ of the 21 soil samples in the correct soil class, while the resistivity values, particularly the inverted subsoil resistivity, enabled the accurate classification of $81 \%$ of the samples. According to the data that were used to elaborate the FDA in Table 3a, two soil samples that were not adequately assigned by the FDA were classified by the soil scientist in the Calcisol map unit, while they should be classified as calcaric Cambisols according to the chemical analyses. Thus, only one sample was incorrectly classified by the FDA with the thermal inertia values.

The study also showed that the V2 array can better discriminate the soil type than the other arrays. Indeed, the V1 array's measurements were influenced by the topsoil horizon, in which structural heterogeneity from plant growth, tillage and the climate can affect electrical measurements (e.g., Seger et al., 2009; Besson et al., 2013). The electrical resistivity 
measurements from the V3 array were more affected by the substrate. Indeed, the soil depth investigation of the V3 array was approximately $0-170 \mathrm{~cm}$, which includes a larger part of the resistant limestone layer than the V2 array. For these two reasons, the V2 array seems to provide the best support for soil mapping in this pedological context, as demonstrated by Moeys et al. 2006.

\section{Extrapolation to the study area and validation}

We used the coefficients of the FDA ranking function (Table 4) to predict the soil type at the plot's extent (Figure 10). The coefficients of the two ranking functions were applied to the thermal inertia grid to obtain two grids values. Then, each pixel was assigned to the category for which the ranking function is highest. We obtained the spatial distribution of the two soil types through the study area. The classification results show an overall percentage of correct classification of $91 \%$ for the 9 ha subplot (Table 5a) and $83.5 \%$ for the whole study area (Table 5b). The decrease in the classification rate with the extension of the area can be explained by the underlying extrapolation of the auger hole soil observations, from which soil scientists usually interpolate the observed characteristics.

\section{Conclusion}

This paper focuses on the assessment of the ability of thermal prospection to discriminate between soil classes. Our findings indicate that thermal inertia data allow the discrimination between two bare soil types in the Beauce region. In addition, the thermal inertia and statistical methodology that was proposed, specifically factorial discriminant analysis, allows an efficient extrapolation of the mapping model beyond the area where it was established. This study provides insights for the spatial mapping of soil types by focusing on thermal airborne remote sensing as an ancillary variable for mapping over large areas. Indeed, 
372 thermal airborne remote sensing presents the advantages of both airborne and ground methods

373 and should be considered and developed in soil studies: in terms of the extent of the

374 investigated surface, this approach fills the gap between ground-based (proximal soil sensing)

375 and satellite techniques.

376 The results of this paper are, to our knowledge, the first direct field-scale comparison

377 between electrical resistivity and thermal inertia data to be published. This paper 378 complements and facilitates the laboratory results in this domain (Singh et al. 2001). These

379 new perspectives in thermal prospecting with new light infrared radiometers will facilitate the

380 cross estimation of electrical and thermal properties, which is very important for engineering 381 applications. 


\section{References}

Beaufrère P., Dabas M., Décriaud J. P., Tabbagh A., 1999. Application de la thermographie aéroportée à la prospection archéologique. Revue archéologique de Picardie, 17, 289293.

Besson A., Seger M., Giot G. and Cousin I. 2013. Identifying the characteristic scales of soil structural recovery after compaction from three in-field methods of monitoring. Geoderma 204-205, 130-139.

Bourennane H., Couturier A., Pasquier C., Chartin C., Hinschberger F., Macaire J.J. and Salvador-Blanes S. 2014. Comparative performance of classification algorithms for the development of models of spatial distribution of landscape structures. Geoderma 119220, 136-144.

Choudury B. J., Isdo S. B. and Reginato R. J. 1986. Analysis of a resistance-energy balance method for estimating daily evaporation from wheat plot using one-time-of-day infrared temperature observation. Remote Sensing of Environment 19, 253-268.

Cousin I., Besson A., Bourennane H., Pasquier C., Nicoullaud B., King D. and Richard G. 2009. From spatial-continuous electrical resistivity measurements to the soil hydraulic functioning at the field scale. Comptes rendus Geoscience 341, 859-867.

Dabas M. 2009. Theory and practice of the new fast electrical imaging system ARPC. In: Seeing the Unseen, Geophysics and Landscape Archaeology, Campana and Piro eds., CRC Press, Taylor and Francis Group, 105-126.

Fourteau A.M. and Tabbagh A. 1979. Parcellaire fossile et prospection thermique: résultat des recherches à Lion en Beauce (Loiret). Revue d'Achéométrie 3, 115-123.

Gebbers R., Lück E., Dabas M. and Domsch H. 2009. Comparison of instruments for geoelectrical soil mapping at the field scale. Near Surface Geophysics 7, 179-190. 
Gauthier F. and Tabbagh A. 1994. The use of airborne thermal remote sensing for soil mapping: a case study in the Limousin Region (France). International Journal of Remote Sensing 15-10, 1981-1989.

Hilker T., Hall F. G., Coops N. C., Coltaz J. G., Black T. A., Tucker C. J., Sellers P. J. and Grant N. 2013. Remote sensing of transpiration and heat fluxes using multi-angle observations. Remote Sensing of Environment 137, 31-42.

IUSS Working Group WRB. 2006. World reference base for soil resources 2006. World Soil Resources Reports No. 103. FAO, Rome, ftp://ftp.fao.org/agl/agll/docs/wsrr103e.pdf

Kahle A. and Rowan L. C. 1980. Evaluation of multispectral middle infrared aircraft images for lithologic mapping in the East Tintic Mountains, Utah. Geology 8, 234-239.

Kappelmeyer O. 1957. The use of near surface temperature measurements for discovering anomalies due to causes at depths. Geophysical Prospecting 5-3, 239-258.

Kato S., Matsunaga T. and Tonooka H. 2014. Statistical and in-situ validations of the ASTER spectral emissivity product at Railroad Valley, Nevada, USA. Remote Sensing of Environment 145, 81-92.

Krcmar B. and Masin J. 1970. Prospecting by the geothermic method. Geophysical Prospecting 18-2, 255-260.

Mallick K., Jarvis A. J., Boegh E., Fisher J. B., Drewery D. T., Tu K. P., Hook S. J., Hulley G., Ardö J., Beringer J., Arain A. and Niyogi D. 2014. A Surface Temperature Initiated Closure (STIC) for surface energy balance fluxes. Remote Sensing of Environment 141, 243-261.

Méhéni Y., Guérin R., Benderitter Y. and Tabbagh A. 1996. Subsurface D.C. resistivity mapping: approximate 1D interpretation. Journal of Applied Geophysics 34, 255-270. 
Moeys J., Nicoullaud B., Dorigny A., Coquet Y. and Cousin I. 2006. Cartographie des sols à grande échelle : Intégration explicite d'une mesure de résistivité apparente spatialisée à l'expertise pédologique. Etude et Gestion des Sols 13(4), 269-286.

Monge J.L. and Sirou R. 1975. ARIES: un radiomètre multi-canal à balayage. 5th Spatial Optics meeting, Société Française d'Optique, Marseille, June 1975, library of L.M.D, Ecole polytechnique, 91128 Palaiseau, France, 14 pp.

Nichols S., Zhang Y. and Ahmad A. 2011. Review and evaluation of remote sensing methods for soil moisture estimation. SPIE Reviews 2 028001, doi:10.1117/1.3534910.

Nicoullaud B., Couturier A., Beaudoin N., Mary B., Coutadeur C. and King D. 2004. Modélisation spatiale à l'échelle parcellaire des effets de la variabilité des sols et des pratiques culturales sur la pollution nitrique agricole. In Organisation spatiale des activités agricoles et processus environnementaux. P. Monestiez, S. Lardon, B. Seguin (eds). Coll. Science Update, INRA Editions, 143-161.

Panissod C., Dabas M., Jolivet A. and Tabbagh A.,1997. A novel mobile multipole system (MUCEP) for shallow (0-3m) geoelectrical investigation: the 'Vol-de-canards' array. Geophysical Prospecting 45, 983-1002.

Périsset M. C. and Tabbagh A. 1981. Interpretation of thermal prospection on bare soils. Archaeometry 23-2, 169-187.

Price J. C. 1977. Thermal inertia mapping: a new view of the earth. Journal of Geophysical Research 82-18, 2582-2590.

Salisbury J. W., Wald A. and D'Aria D. 1994. Thermal infrared remote sensing and Kirchhoff's law 1. Laboratory measurements. Journal of Geophysical Research 99-B6, 11897-11911.

Samouelian A., Cousin I., Tabbagh A., Bruand A. and Richard G. 2005. Electrical resistivity survey in soil science: a review. Soil \& Tillage Research 83, 173-193. 
Schlerf M., Rock G., Lagueux P., Ronellenfitsch F., Gehards M., Hoffmann L. and Udelhoven T. 2012. A hyperspectral thermal infrared imaging instrument for natural resources applications. Remote Sensing 4, 3995-4009.

Scollar I., Tabbagh A., Hesse A. and Herzog I. 1990. Archaeological prospecting and remote sensing. Cambridge University Press, 674p.

Seger, M., Cousin, I., Frison, A., Boizard, H. and Richard, G. 2009. Characterisation of the structural heterogeneity of the soil tilled layer by using in situ 2D and 3D electrical resistivity measurements. Soil and Tillage Research 103 (2), 387-398.

Singh N. D., Kuriyan S. J. and Chakravarthy M.. C. 2001. A generalized relationship between electrical and thermal resistivities. Experimental Thermal and Fluid Science 25, 175181.

Tabachnick B.G. and Fidell L.S. 1996. Using Multivariate Statistics, Harper Collins, New York.

Tabbagh A. 1973. Essai sur les conditions d'application des mesures thermiques à la prospection archéologique. Annales de Géophysique 29, 179-188.

Tabbagh A. 1976. Les propriétés thermiques des sols: premiers résultats utilisables en prospection archéologique. Archaeo-Physika, Band 6, 127-149.

Tomassone R., Danzart M., Daudin J.J. and Masson J.P. 1988. Discrimination et Classement. Masson, Paris.

Viscarra Rossel R. A., McBratney A. and MinassyB. (Eds), 2010. Proximal Remote Sensing. Springer, 448p.

Watson K., Rowan L. C., Bowers T. L., Anton-Pacheo C., Gumiel P. and Miller S. H. 1996. Lithologic analysis from multispectral infrared data of the alkali rock complex at Iron Hill, Colorado. Geophysics 61-3, 706-721. 


\section{Figure captions}

482

483

Figure 1: Soil map of plot A with the location of the zone B

484

485

486

Figure 2: View of the ARPC system, with the geometrical scheme of the location of the 8 electrodes.

487

488

Figure 3: Zone B: apparent resistivity maps for the three ARP® channels, with the location of the auger-drilled holes, the data of which are used in the statistical analyses. The resistivity of

490

491

492

493

494

495

496

497

498

499

500

501

502

503

504 the subsoil layer is calculated assuming the topsoil has a $40 \Omega \mathrm{m}$ resistivity and a $0.25 \mathrm{~m}$ thickness, the apparent thermal inertia of the subsoil layer is calculated assuming the same thickness, a $0.4810^{-6} \mathrm{~m}^{2} \mathrm{~s}^{-1}$ diffusivity and a 1732 S.I. thermal inertia.

Figure 4: Localization of the auger holes' soil textures in CEC85 triangle.

Figure 5: Variation in the auger holes $\mathrm{CaCO}_{3}$ content.

Figure 6: Heat flux in the ground at the Bricy meteorological station from November 15, 2002 to December 15, 2002. The arrow corresponds to the measurement time.

Figure 7: Apparent thermal inertia of the subsoil layer as deduced from the brightness temperature in the $10.5-12.5 \mu \mathrm{m}$ channel (left), and the limits of plot A and zone B.

Figure 8: Flowchart of the developed approach. 
506 Figure 9a: PCA on topsoil data.

507

508 Figure 9b: PCA on subsoil data.

509

510 Figure 10: Soil types that were inferred from the ranking functions of the FDA.

511 


\section{Table captions}

514

515 Table 1: ANOVA results of thermal inertia and soil type (haplic Calcisol and calcaric

516 Cambisol) punctual data (21 soil auger holes).

517

518 Table 2: ANOVA results of subsoil resistivity and soil type (haplic Calcisol and calcaric

519 Cambisol) punctual data (21 soil auger holes).

520

521 Table 3: Confusion matrix from factorial discriminant analysis between the two soil types and

522 the subsoil thermal inertia values (a), subsoil inverted resistivity values (b) and apparent

523 resistivity (c to e).

524

525 Table 4: Factorial discriminant analysis: coefficients of the ranking functions.

526

527 Table 5: Discrepancy between soil types from discriminant functions and the reference soil

528 map: (a) zone B, (b) plot A.

529 


\section{Appendix I: Glossary}

532

533

534

535

536

537

538

539

540

541

542

543

544

545

546

547

548

549

550

551

552

553

554

555

Statistical methods

ANOVA: Analysis of variance, a test that verifies whether several samples belong to the same population.

DF: The degrees of freedom for the model, equal to one less than the number of categories

F ratio, $\operatorname{Pr}>$ F: The test statistic that is used to decide whether the sample means are within the sampling variability.

Sum of Squares: Sum of the squared differences between each observation and the overall mean.

Mean Squares: Sums of Squares divided by the corresponding degrees of freedom.

FDA: Factorial discriminant analysis, assigns to pre-defined classes by using discriminant variables.

PCA: Principal Component Analysis, uses an orthogonal transformation to convert a set of observations of correlated variables into a set of values of linearly uncorrelated variables called principal components.

\section{Thermal instrument and parameters}

Radiometer: An instrument that measures the radiant flux of electromagnetic waves - in this case, the infrared band - from the photo-conductive effect.

Brightness temperature: temperature of the black body emitting the same radiation intensity.

Thermometric temperature: temperature which would be measured by a thermometer in close contact with the soil surface (in other words the brightness temperature if the emissivity is 1.)

Emissivity: ratio between the radiance emitted by a given surface to the radiation that would be emitted by the black body surface at the same thermometric temperature. In the present case the emissivity is considered for the thermal infrared spectrum band $10.5-12.5 \mu \mathrm{m}$. 
Thermal conductivity, $K$ : This property is defined by the Fourier law as the opposite of the ratio of the heat flux to the temperature gradient. Its SI unit is $\mathrm{Wm}^{-1} \mathrm{~K}^{-1}$.

Volumetric capacity, $\boldsymbol{C}_{\boldsymbol{v}}$ : This property expresses the ability of heat storage. It is defined as the ratio of the variation in the stored heat to the corresponding temperature variation. Its SI unit is $\mathrm{Jm}^{-3} \mathrm{~K}^{-1}$.

Thermal diffusivity, $\Gamma$ : This property is defined by $\Gamma=K / C_{v}$ and governs the temperature behavior in unsteady regimes. Its SI unit is $\mathrm{m}^{2} \mathrm{~s}^{-1}$.

Thermal inertia, $P$ : $P=\sqrt{K C_{v}}$. The unsteady temperature changes at the surface of a body are inversely proportional to $P$. Its SI unit is $\mathrm{Jm}^{-2} \mathrm{~K}^{-1} \mathrm{~s}^{-0.5}$.

\section{Appendix II: Variable descriptions}

clay: Percentage of clay in the soil sample, parameter of soil texture, particle diameter below $0.002 \mathrm{~mm}$

silt: Percentage of silt in the soil sample, parameter of soil texture, particle diameter from 0.002 to $0.05 \mathrm{~mm}$

sand: Percentage of sand in the soil sample, parameter of soil texture, particle diameter from 0.05 to $2 \mathrm{~mm}$

$\mathrm{CaCO}_{3}$ : Percentage of calcium carbonate in the soil sample

V1: Apparent resistivity in $\Omega . m$, measured by the first channel (A B-M1 N1)

V2: Apparent resistivity in $\Omega . \mathrm{m}$, measured by the second channel (A B-M2 N2)

V3: Apparent resistivity in $\Omega . \mathrm{m}$, measured by the third channel (A B-M3 N3)

ISR: Inverted subsoil resistivity, calculated from the two layer $1 \mathrm{D}$ model with a $40 \Omega$.m resistivity and $0.25 \mathrm{~m}$-thick first layer

\section{Appendix III}


581 To determine the flux $Q(t)$ at the ground surface, it is split into a series of step functions

582 beginning at a regular interval $\delta t$ so that at time $t_{i}=i \delta t$ the temperature of a homogeneous soil

$583 T(z, t)$ is written as follows:

$584 T(z, t)=\frac{2}{P}\left\{\sum_{l=2}^{i-1}\left(Q_{l}-Q_{l-1}\right) S(z, i-l)+Q_{1} S(z, i-1)\right\}$, where $S(z, m)=\sqrt{m \delta t} . i e r f c\left(\frac{z}{2 \sqrt{\Gamma m \delta t}}\right)$,

$585 P$ is the thermal inertia and $\Gamma$ the thermal diffusivity and $Q_{l}$ the successive values of $Q(t)$ and

586 ierfc the integral of the complementary error function: $\operatorname{ierfc}(x)=\int_{x}^{\infty} \operatorname{erfc}(u) d u$, and

$587 \operatorname{erfc}(x)=\frac{2}{\sqrt{\pi}} \int_{x}^{\infty} e^{-u^{2}} d u$. These monotonous functions are calculated by their series

588 development.

589 The successive values of the flux are then calculated step by step from the temperature

590 differences. The calculation can be applied with only one depth:

$591 \quad Q_{1}=(T(z, \delta t)-T(z, 0)) \frac{P}{2 S(z, 1)}$, then

$592 Q_{2}=\frac{(T(z, 2 \delta t)-T(z, \delta t)) P / 2-Q_{1}(S(z, 2)-S(Z, 1))}{S(z, 1)}$, and so on.

593 Using J different depths one must apply the least squares method and one has:

$594 \quad Q_{1}=\frac{P}{2} \frac{\sum_{j=1}^{J}\left(T\left(z_{j}, \delta t\right)-T\left(z_{j}, 0\right)\right) S\left(z_{j}, 1\right)}{\sum_{j=1}^{J} S^{2}\left(z_{j} 1\right)}$, and so on. 


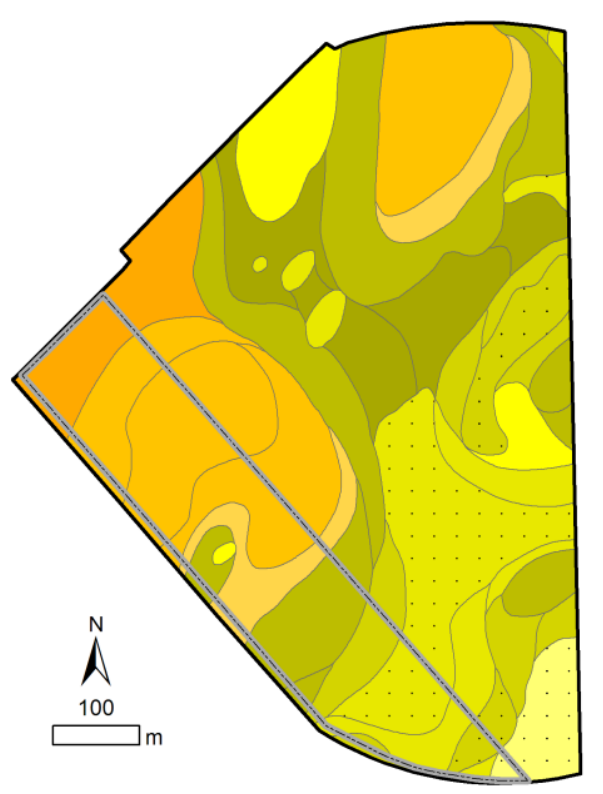

$\square$ zone B :resistivity area

$\operatorname{plot} A$

\section{SOIL TYPE}

HAPLIC CALCISOL developed over beige and grey cryoturbed materi HAPLIC CALCISOL developed over beige cryoturbed material at med HAPLIC CALCISOL developed over beige cryoturbed material at shall Stony CALCARIC CAMBISOL developed over hard limestone Stony CALCARIC CAMBISOL developed over soft limestone Stony CALCARIC CAMBISOL developed over soft limestone CALCARIC CAMBISOL developed over hard limestone CALCARIC CAMBISOL developed over grey limestone CALCARIC CAMBISOL developed over soft limestone CALCARIC CAMBISOL developed over beige cryoturbed material

CALCARIC CAMBISOL developed over beige and grey cryoturbed me
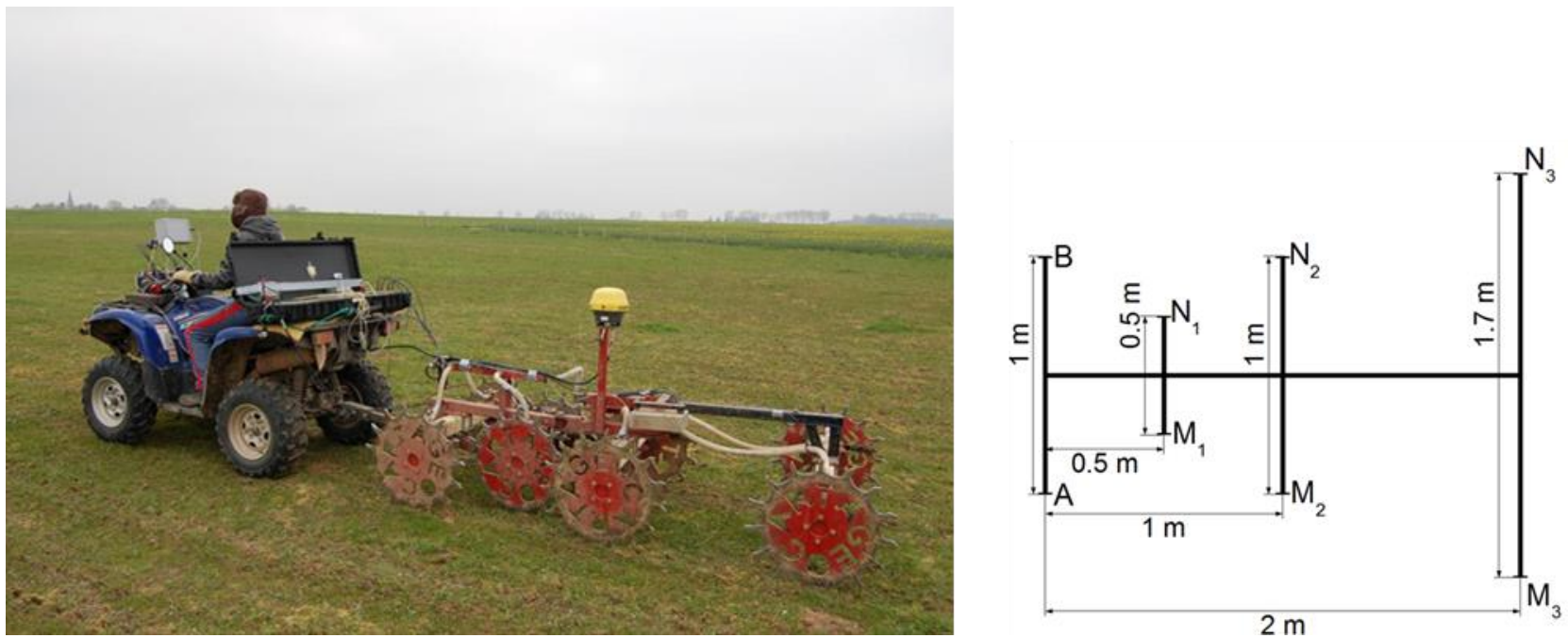

Figure 2 

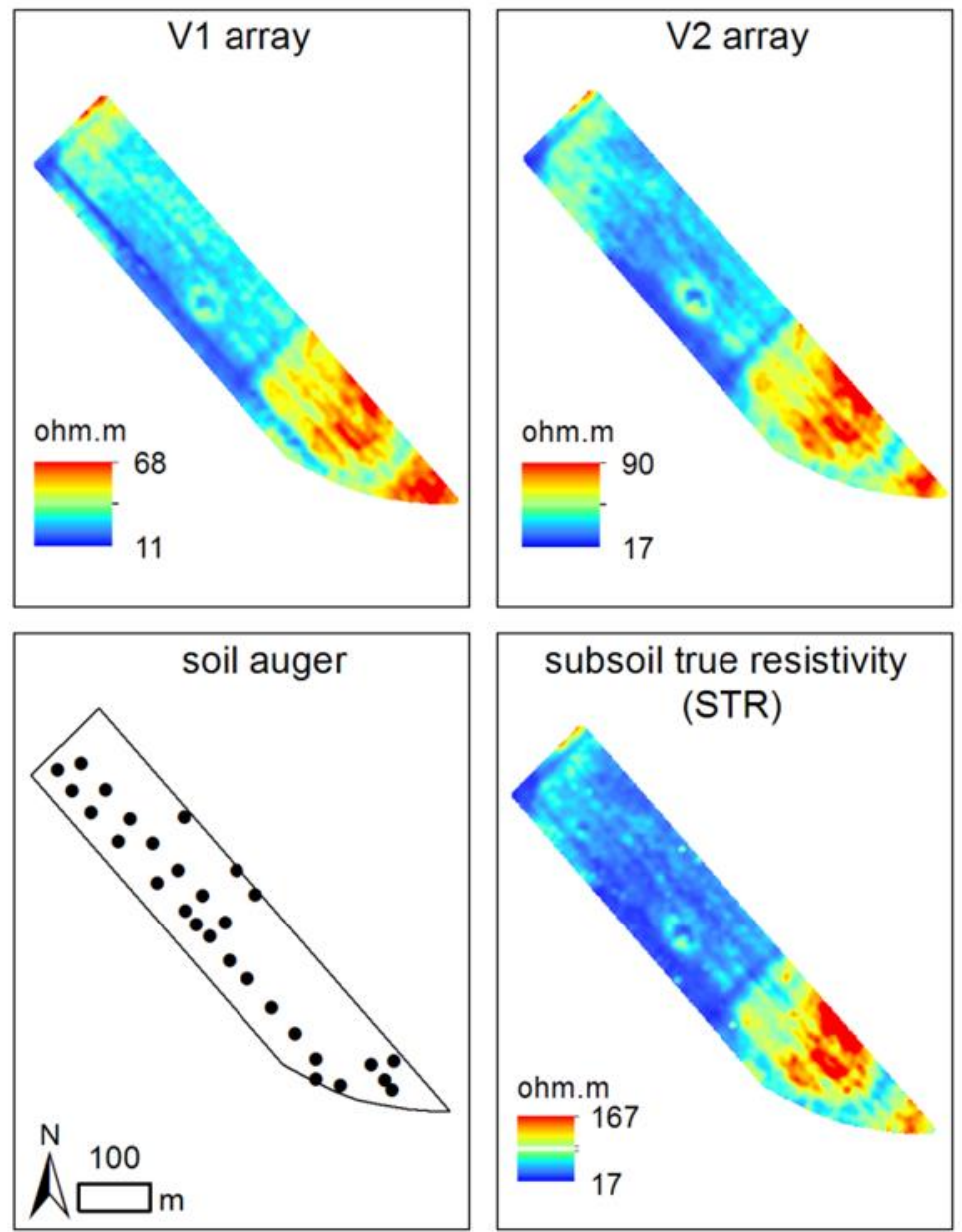
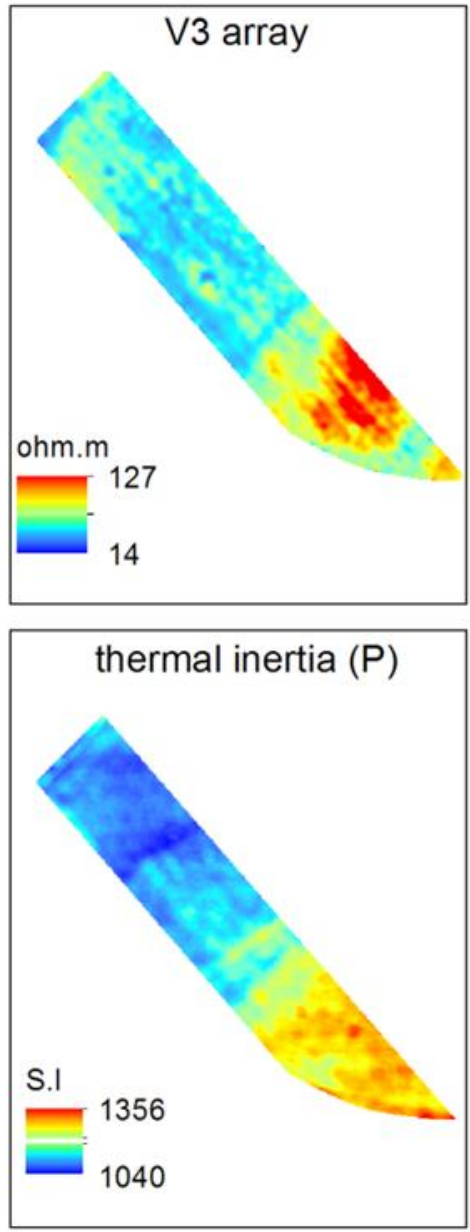

606

607

Figure 3 

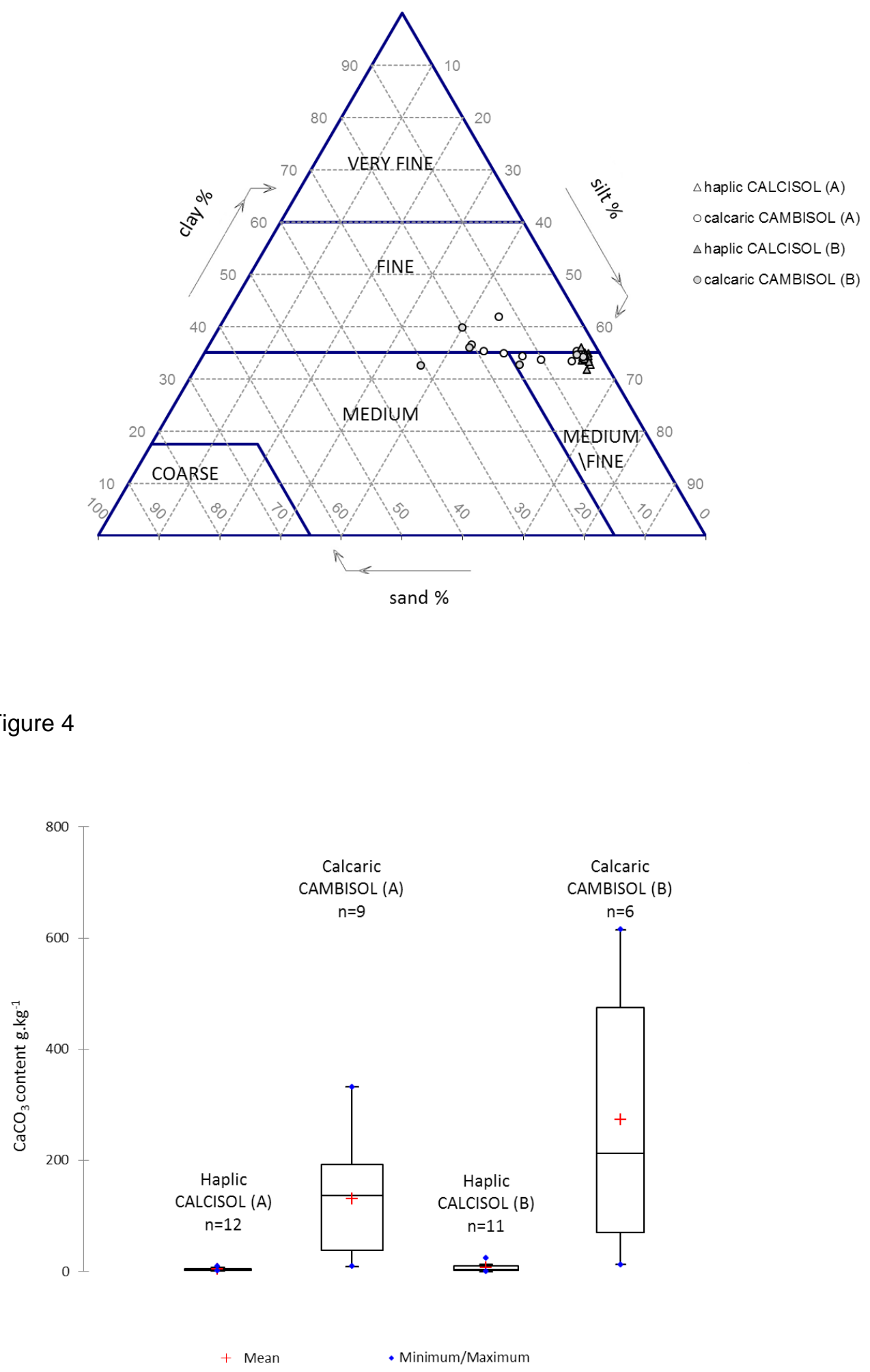

611 Figure 5 


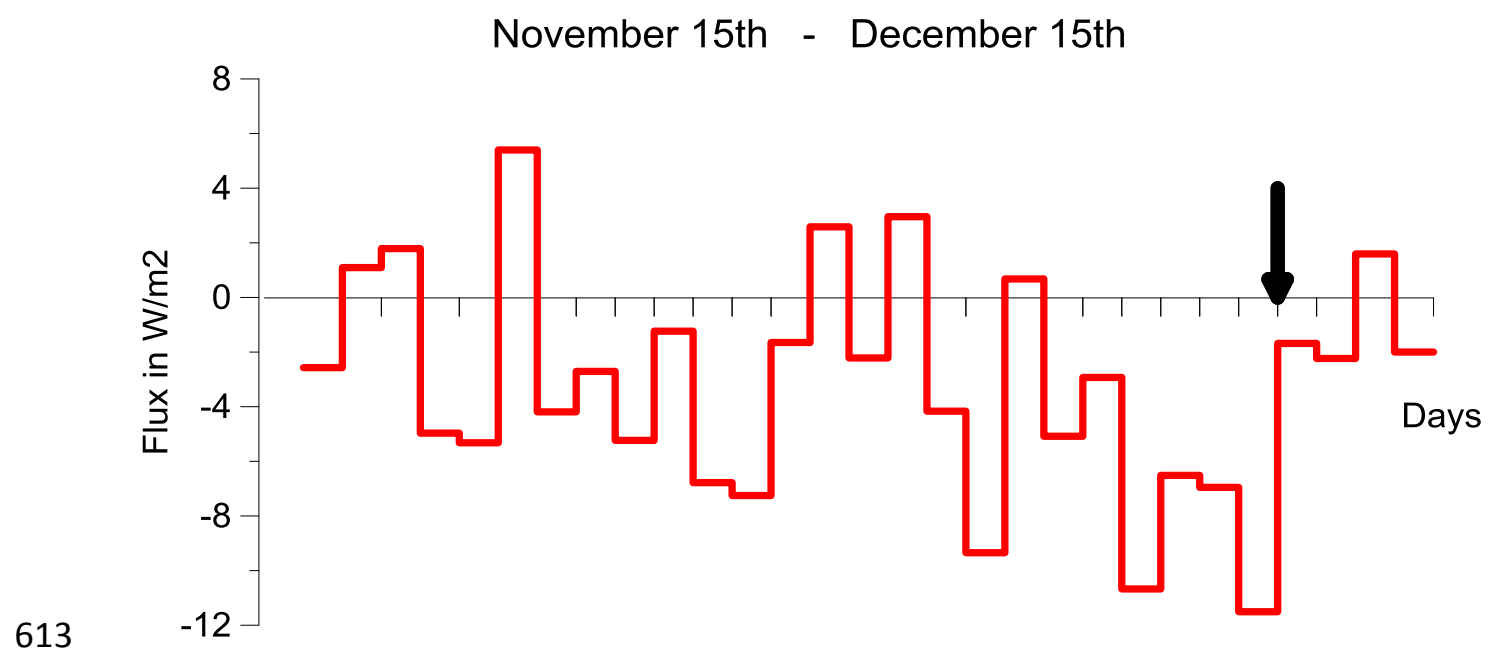

614 Figure 6

615

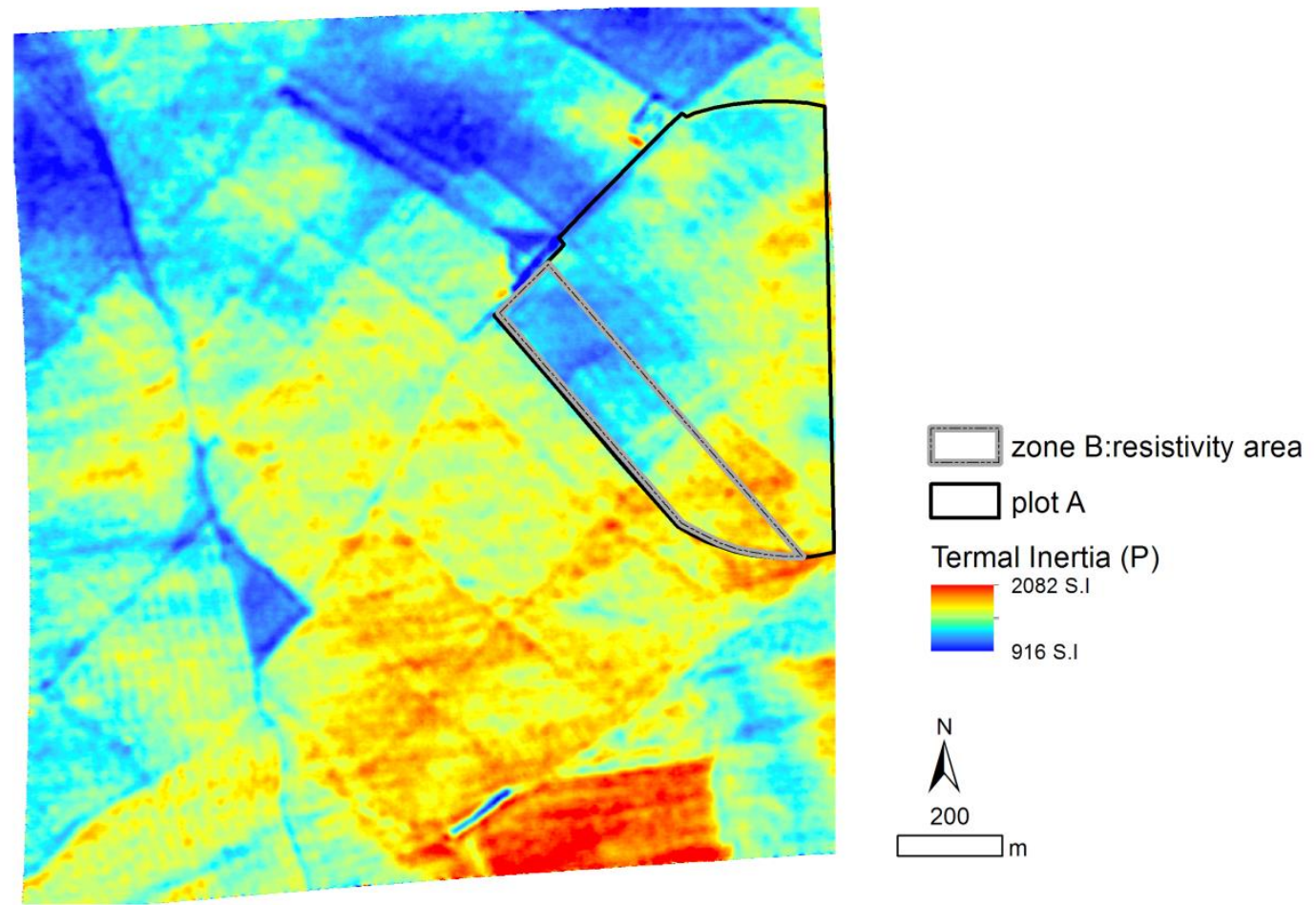

616

$617 \quad$ Figure 7

618

619 
Study sites:

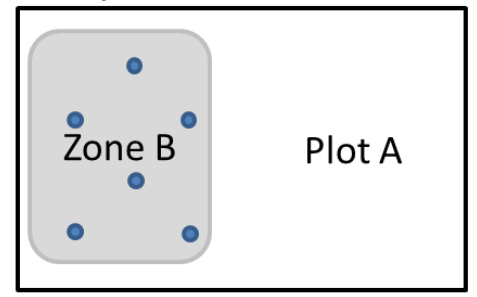

Data set :

\begin{tabular}{|c|}
\hline Zone B \\
Punctual analysis \\
\hline - electrical resistivity \\
prospection, 3 depths \\
- soil analysis (21 pits) \\
\hline
\end{tabular}

Plot A (zone B included) Spatial analysis

- thermal prospection

- soil map

Data analysis :

\begin{tabular}{|l|l|} 
- descriptive statistics : PCA \\
Data : soil - resistivity - thermal inertia \\
measurements: Anova analysis
\end{tabular}




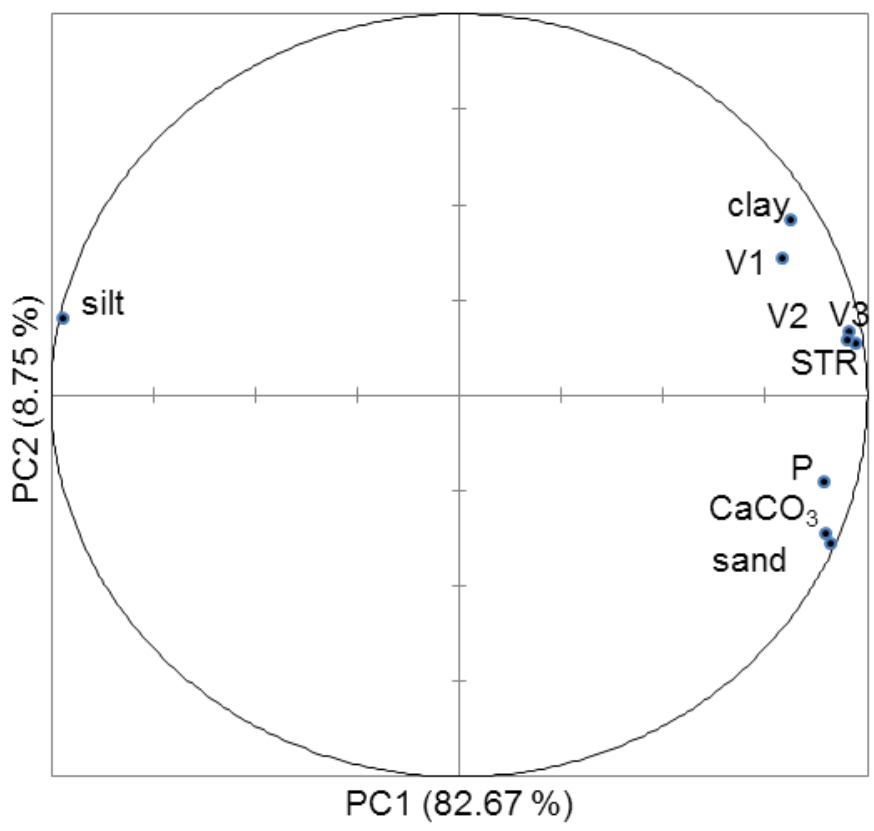

628 Figure 9a

629

630

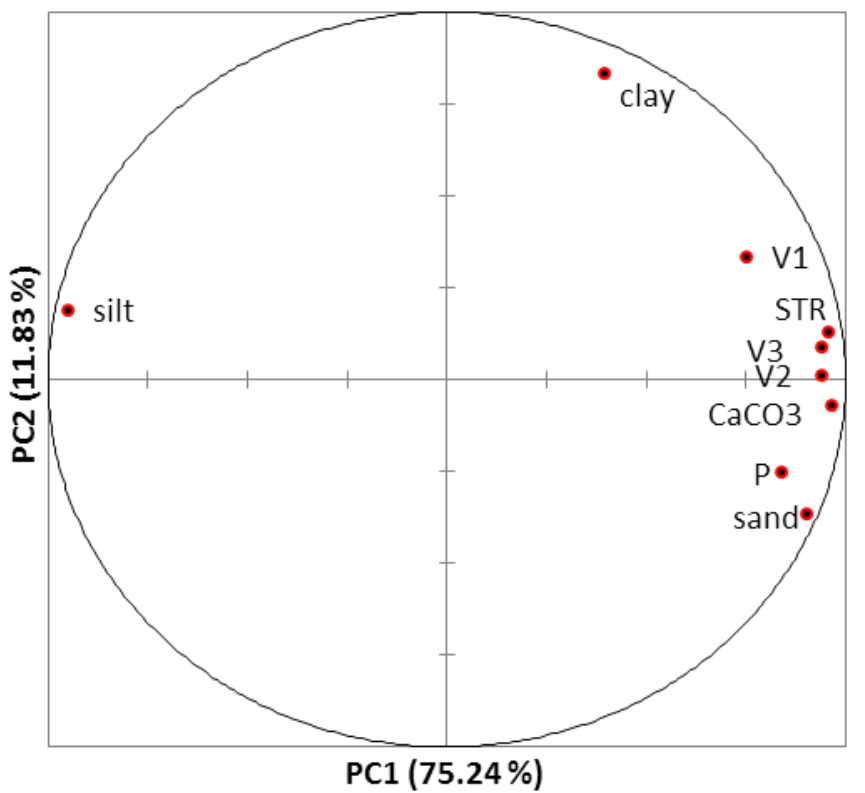

631 Figure 9b

632

633 


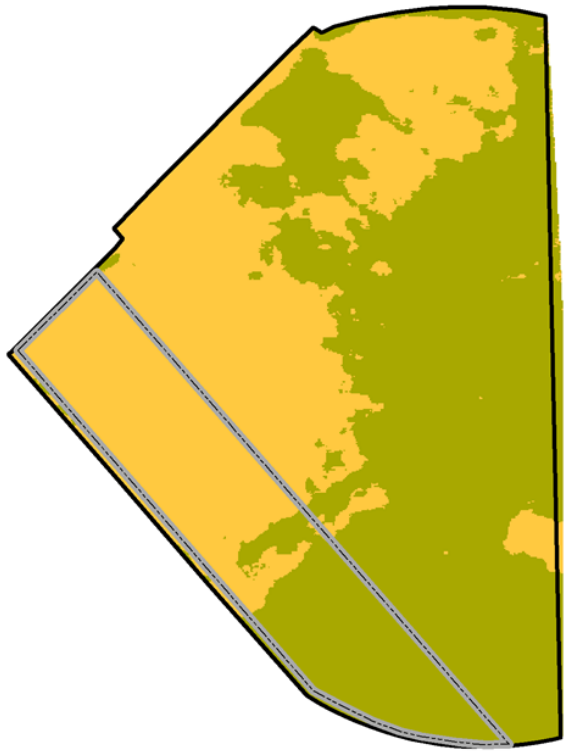

$\square$ zone B:resistivity area

$\square$ plot A

$\square$ haplic Calcisol

calcaric Cambisol

$\AA^{N}$

$100 \mathrm{~m}$

634

635 Figure 10

636 
ANOVA analysis

\begin{tabular}{lccccc}
\hline Source of variation & DF & $\begin{array}{c}\text { Sum of } \\
\text { squares }\end{array}$ & $\begin{array}{c}\text { Mean } \\
\text { square }\end{array}$ & F-ratio & $\operatorname{Pr}>$ F \\
\hline Model & 1 & 58188.011 & 58188.011 & 20.744 & 0.000 \\
Error & 20 & 56101.097 & 2805.055 & & \\
Total & 21 & 114289109.000 & & & \\
\hline
\end{tabular}

\begin{tabular}{lccc}
\hline \multicolumn{1}{c}{ Modality } & Estimated mean & \multicolumn{2}{c}{ Groups } \\
\hline calcaric Cambisol & 1211.977 & A & \\
haplic Calcisol & 1108.692 & & B \\
\hline
\end{tabular}

639

640

641 Table 1

642

ANOVA analysis

\begin{tabular}{lccccc}
\hline Source of variation & DF & $\begin{array}{c}\text { Sum of } \\
\text { squares }\end{array}$ & $\begin{array}{c}\text { Mean } \\
\text { square }\end{array}$ & F-ratio & $\operatorname{Pr}>$ F \\
\hline Model & 1 & 1743.219 & 1743.219 & 15.143 & 0.001 \\
Error & 20 & 2302.408 & 115.120 & & \\
Total & 21 & 4045.627 & & & \\
\hline
\end{tabular}

\begin{tabular}{|c|c|c|}
\hline Modality & Estimated mean & Groups \\
\hline calcaric Cambisol & 48.776 & $A$ \\
\hline haplic Calcisol & 30.899 & B \\
\hline
\end{tabular}

643

Table 2

644 


\begin{tabular}{lcccc} 
Category & h. Calcisol & c. Cambisol & total & $\begin{array}{r}\text { \% of correct } \\
\text { classification }\end{array}$ \\
\hline $\begin{array}{l}\text { (a) thermal inertia }(P) \\
\text { haplic Calcisol }\end{array}$ & 11 & 1 & 12 & 91.7 \\
calcaric Cambisol & 2 & 7 & 9 & 77.8 \\
\hline total & 13 & 8 & 21 & 85.7
\end{tabular}

(b) subsoil interpreted

resistivity

$\begin{array}{lllll}\text { haplic Calcisol } & 12 & 0 & 12 & 100\end{array}$

\begin{tabular}{lcccc} 
calcaric Cambisol & 4 & 5 & 9 & 55.6 \\
\hline total & 16 & 5 & 21 & 80.9
\end{tabular}

(c) apparent resistivity, $V 1$

\begin{tabular}{lcccc} 
haplic Calcisol & 10 & 2 & 12 & 83.33 \\
calcaric Cambisol & 4 & 5 & 9 & 55.56 \\
\hline total & 14 & 7 & 21 & 71.43
\end{tabular}

(d) apparent resistivity, V2

\begin{tabular}{lcccc} 
haplic Calcisol & 10 & 2 & 12 & 83.33 \\
calcaric Cambisol & 2 & 7 & 9 & 77.78 \\
\hline Total & 12 & 9 & 21 & 80.95
\end{tabular}

(e) apparent resistivity, V3

\begin{tabular}{lcccc} 
haplic Calcisol & 12 & 0 & 12 & 100 \\
calcaric Cambisol & 4 & 5 & 9 & 55.56 \\
\hline total & 16 & 5 & 21 & 80.95
\end{tabular}

647 Table 3

648

649

\begin{tabular}{lrr}
\hline & \multicolumn{1}{c}{ haplic } & \multicolumn{1}{c}{ calcaric } \\
& Calcisol & \multicolumn{1}{c}{ Cambisol } \\
\hline Constant & -219.099 & -259.660 \\
$\mathrm{P}$ & 0.394 & 0.429 \\
\hline
\end{tabular}

650

651 
652

\begin{tabular}{|c|c|c|c|c|}
\hline Category & haplic Calcisol & calcaric Cambisol & total & $\begin{array}{l}\% \text { of correct } \\
\text { classification }\end{array}$ \\
\hline \multicolumn{5}{|l|}{ (a) zone B } \\
\hline haplic Calcisol & 46256 & 5058 & 51314 & 90.1 \\
\hline calcaric Cambisol & 2828 & 32893 & 35721 & 92.1 \\
\hline total & 49084 & 37951 & 174070 & 90.9 \\
\hline \multicolumn{5}{|l|}{ (b) plot A } \\
\hline haplic Calcisol & 116246 & 53789 & 170035 & 68.4 \\
\hline calcaric Cambisol & 11126 & 212627 & 223753 & 95.0 \\
\hline total & 127372 & 266416 & 787576 & 83.5 \\
\hline
\end{tabular}

653

654 Table 5

655

656 